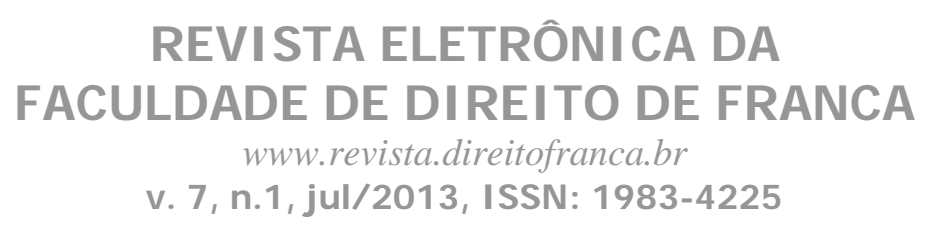

\title{
A PRIVATIZAÇÃO DA DEFESA DO MEIO AMBIENTE: UMA VISÃO DERIVADA DO NOVO CÓDIGO FLORESTAL
}

Renato Maso Previde

http://buscatextual.cnpq.br/buscatextual/visualizacv.do?id=K4745416A9

\begin{abstract}
Resumo: As transformações das normas jurídicas são ditadas de acordo com o clamor da sociedade, em que, dependendo de seus interesses e necessidades, estas alterações são realizadas de forma mais célere ou não.

Esta é a base do presente trabalho, pois através destas alterações (mutações), o microssistema jurídico ambiental conta com a convergência das disposições legais anteriores com a do atual texto do novo Código Florestal, o que não acontecia com o pretérito Código Florestal, em que sequer guardava sintonia com o que preceitua a Política Nacional de Meio Ambiente (Lei $\mathrm{n}^{\circ}$ 6938/81).

Entretanto, para esta necessária convergência legal e de interesses foi essencial implementar o conceito de conservação, deixando a ideia de preservação para o antigo código, gerando o surgimento de novos institutos que coadunam a conservação com o desenvolvimento sustentável, sendo, em nosso ponto de vista, a verdadeira chance de manutenção de áreas verdes, que passarão a possibilitar ao seu proprietário a manutenção ativa da área, deixando de lado o peso que assolava os produtores, pois a determinação legal cogente era a de tratá-las, na grande maioria das vezes, como improdutivas, resultando apenas em ônus para seus detentores.
\end{abstract}

Palavras-chave: Novo Código Florestal - Privatização - Defesa - Meio Ambiente

The Privatization of Environmental Defense: A Derivative View of the New Forest Code

\begin{abstract}
The transformations of the legal rules are dictated according to the clamor of society, in which, depending on their interests and needs, such changes are performed more quickly or not. This is the basis of this work, since through these changes (mutations), the legal environmental microsystem counts on the convergence of laws prior to the actual text of the new Forest Code, that did not use to happen with the past Forest Code, in which there were no accordance to the provisions of the National Policy on the Environment (Law No. 6938/81).

However, for this legal and interests necessary convergence it was essential to implement the concept of conservation, leaving the idea of preserving for the past Code, generating the emergence of new institutes that put in line the conservation with sustainable development, which is in our view the real chance of maintaining green areas, that which will allow their owners to maintain the area active, leaving aside the weight that plagued producers, because the cogent legal determination was to treat them, in most cases, as unproductive, resulting only in cost to their holders.
\end{abstract}

Keywords: New Forest Code, Privatization, Defense, Environment. 


\section{REVISTA ELETRÔNI CA DA \\ FACULDADE DE DI REITO DE FRANCA \\ www.revista.direitofranca.br \\ v. 7, n.1, jul/ 2013, I SSN: 1983-4225}

\section{INTRODUÇÃO}

O Direito representa uma ciência na qual sua configuração decorre de acordo com os desígnios do povo em que está inserido.

Com isto, as transformações das normas jurídicas são ditadas de acordo com o clamor da sociedade, em que, dependendo de seus interesses e necessidades, estas alterações são realizadas de forma mais célere ou não.

Exemplificando estas questões, temos os procedimentos legislativos distintos para alteração do próprio texto da Constituição Federal ou de uma Lei Ordinária.

Verifica-se que a regra para esta mudança tanto para uma quanto para outra são bem destoantes, pois esbarram na segurança jurídica necessária a amparar o conteúdo normativo amparado por cada uma. Se a Constituição Federal possui como requisitos essenciais para sua emenda a aprovação desta proposta por três quintos dos votos de cada Casa do Congresso Nacional, em um contraponto tem-se o singelo quórum para aprovação de uma Lei Ordinária, que necessita apenas de maioria simples.

Outro ponto que enfoca a alteração, não da norma, mas de sua interpretação, está vinculada à sua apreciação aos Tribunais, que através de jurisprudências, retomam, mantêm ou inovam determinado entendimento sobre casos concretos.

Vislumbramos, portanto, dois nítidos sistemas denominados por Tavares $^{1}$ de mutação formal e mutação material, isto no campo constitucional.

A mutação formal decorre do processo legislativo e toda sua formalidade expressa na Constituição Federal.

Dos artigos 59 a 69 da Constituição Federal há um fechado sistema de elaboração e alteração de Emendas Constitucionais e Leis, que privilegiam a segurança jurídica da sociedade, que representada na figura do Poder Legislativo, possui uma salvaguarda quanto a possíveis alterações da legislação de forma arbitrária ou ainda à previsão de normas de exceção apenas a certos grupos da sociedade.

${ }^{1}$ TAVARES, André Ramos. Curso de direito constitucional. 5 ed. São Paulo: Saraiva, 2007, p. 207. 


\title{
REVI STA ELETRÔNI CA DA \\ FACULDADE DE DI REITO DE FRANCA \\ www.revista.direitofranca.br \\ v. 7, n.1, jul/ 2013, I SSN: 1983-4225
}

Bulos enfatiza a necessidade de um padrão normativo quando comenta o seguinte ${ }^{2}$ :

\begin{abstract}
Assim, ninguém é obrigado a fazer ou deixar de fazer alguma coisa sem a existência de um comando normativo, feito à luz do processo legislativo propriamente constitucional, nem submetido a juiz ou tribunal sem as garantias instrumentais, previstas na Constituição e nas leis da República.
\end{abstract}

Da forma como exposto, entendemos que a necessidade de um sistema fechado e previsto no texto constitucional para a elaboração e alteração da legislação reflete a necessidade e objetivo da Constituição Federal em proteger o cidadão de um sistema repressivo e inquisitório, que vigeu até a década de 80 em nosso País.

Sobre a mutação material, esta está ligada à transformação quanto à interpretação da Lei, ou seja, ausente sua alteração no próprio texto legislativo, tornando a análise dos Tribunais uma forma de garantir os direitos da sociedade e a manutenção da própria Lei, lhe entregando um sentido mais adequado ao contexto do ordenamento jurídico.

No entanto, entendemos estas não são as únicas formas de alteração da legislação e da interpretação a ser utilizada na aplicação desta sobre o caso concreto, tendo em vista que o clamor popular ou até mesmo o desenvolvimento cultural e educacional de uma população leva a esta nova visão sobre um mesmo tema.

Diante disso, notamos a necessidade em qualificar esta mutação na aplicação da lei como algo que pode ainda ser anterior a um novo processo legislativo e até mesmo à formação de nova jurisprudência, denotando um caráter iniciador deste movimento através da formação e desenvolvimento de um povo, o que consideramos por designar esta alteração de mutação popular, pois derivada do povo seja representado por pensadores, técnicos, empresários ou por qualquer outro ramo.

E atualmente é o que acompanhamos nas aplicações da legislação ambiental sobre os casos concretos, em certo momento determinado pela necessidade financeira em conter rombos aos cofres públicos ou em outro momento pela premente necessidade na geração de empregos para aplacar a necessidade de uma população, que necessariamente, não vem dizer em prejuízo

\footnotetext{
${ }^{2}$ BULOS, Uadi Lammêgo. Curso de direito constitucional. São Paulo: Saraiva, 2007, p. 941.
} 


\section{REVI STA ELETRÔNI CA DA \\ FACULDADE DE DI REITO DE FRANCA \\ www.revista.direitofranca.br \\ v. 7, n.1, jul/ 2013, I SSN: 1983-4225}

ao meio ambiente, mas em uma convergência de interesses para sua manutenção, propiciando a utilização do locus como um ambiente também favorável ao desenvolvimento humano.

Esta é a base do presente trabalho, pois através destas alterações (mutações), o microssistema jurídico ambiental conta com a convergência das disposições legais anteriores com a do atual texto do novo Código Florestal, o que não acontecia com o pretérito Código Florestal, em que sequer guardava sintonia com o que preceitua a Política Nacional de Meio Ambiente (Lei $\left.n^{\circ} 6938 / 81\right)$.

Entretanto, para esta necessária convergência legal e de interesses foi essencial implementar o conceito de conservação, deixando a ideia de preservação para o antigo código, gerando o surgimento de novos institutos que coadunam a conservação com o desenvolvimento sustentável, sendo, em nosso ponto de vista, a verdadeira chance de manutenção de grandes áreas verdes, que passarão a possibilitar ao seu proprietário a manutenção ativa da área, deixando de lado o peso que assolava os produtores, pois a determinação legal cogente era a de tratá-las, na grande maioria das vezes, como improdutivas.

\section{A MUTABILIDADE DOS CONCEITOS DE MEIO AMBIENTE}

\subsection{A MUTABILIDADE MATERIAL}

\subsubsection{CONSERVACIONISMO: UM NOVO PARADIGMA PARA O MEIO AMBIENTE EM COMPLEMENTAÇÃO AO PRESERVACIONISMO.}

O direito posto vem estruturado em normas-conceito e normas-princípios, sendo que destas últimas, trataremos em outro momento.

As normas-conceito podem derivar de um conteúdo pré-determinado ou vago, dependendo do interesse social e da mutabilidade a ser imposta sobre a norma em comento.

Como não poderia ser diferente, o Direito Ambiental sempre se amparou em tais normas com a finalidade de expor sua visão de futuro e de tutela da pretensão protetiva do meio ambiente. 


\section{REVISTA ELETRÔNI CA DA \\ FACULDADE DE DI REITO DE FRANCA \\ www.revista.direitofranca.br \\ v. 7, n.1, jul/ 2013, I SSN: 1983-4225}

Decorre, que o sentido desta tutela variou muito entre aquilo que a legislação prédeterminava e o anseio de uma parcela da população, dividindo estas vontades em dois ramos distintos: o preservacionismo e o conservacionismo.

O legado deixado pelas primeiras instituições que nasceram em prol do meio ambiente e que ainda continuam a difundir conhecimentos ambientais iniciou-se nas décadas de 60 e 70 com a ideia estruturante da não agressão ao meio ambiente, surgindo o conceito de preservacionismo.

Nos dizeres de Sirvinskas, preservar é a proibição da exploração econômica dos recursos naturais. $^{3}$

Esta visão veio a colidir com os interesses, não só dos particulares, mas também daqueles referentes ao Estado, pois a estes a visão de desenvolvimento está ligada à ideia de produção de meios de consumo, premeditado por intermédio de um longo discurso econômico voltado à doutrina dominante de nossa época: o capitalismo.

Esta é uma das facetas maléficas do Estado, pois utiliza de uma errônea imposição tributária para o crescente aporte financeiro aos cofres públicos, decorrentes da má gestão administrativa, confrontando diretamente com a necessidade do Estado em proteger o meio ambiente como bem de uso comum do povo e essencial para a sua qualidade de vida, conforme estatui o artigo 225 da Constituição Federal.

A demonstração desta dualidade do Estado (arrecadatório X protetor) consubstancia na existência de interesses colidentes, que denominamos de interesses secundários e interesses primários, respectivamente, de acordo com exposição realizada no parágrafo anterior.

Em lapidar ensinamento, Bandeira de Mello leciona o seguinte:

É que, além de subjetivar interesses, o Estado, tal como os demais particulares, é, também ele, uma pessoa jurídica, que, pois, existe e convive no universo jurídico em concorrência com todos os demais sujeitos de direito. Assim, independentemente do fato de ser, por definição, encarregado dos interesses públicos, o Estado pode ter, tanto quanto as demais pessoas, interesses que lhe são particulares, individuais, e que, tal como os interesses delas, concebidas em suas meras individualidades, se encarnam no Estado enquanto pessoa. Esses últimos não são interesses públicos, mas interesses individuais do Estado, similares, pois (sob o prisma extrajurídico), aos interesses de qualquer outro sujeito. Similares, mas não iguais. Isto porque a generalidade de tais sujeitos pode defender estes interesses individuais, ao passo que o Estado, concebido que

\footnotetext{
${ }^{3}$ SIRVINSKAS, Luis Paulo. Manual de direito ambiental. Ed. 9. São Paulo: Saraiva, 2011, p. 62.
} 


\section{REVI STA ELETRÔNI CA DA \\ FACULDADE DE DI REITO DE FRANCA \\ www.revista.direitofranca.br \\ v. 7, n.1, jul/ 2013, I SSN: 1983-4225}

é para a realização dos interesses públicos (situação, pois, inteiramente diversa da dos particulares), só poderá defender seus próprios interesses privados quando, sobre não chocarem com os interesses públicos propriamente ditos, coincidam com a realização deles. Tal situação ocorrerá sempre que a norma donde defluem os qualifique como instrumentais ao interesse público e na medida em que o sejam, caso em que sua defesa será, ipso facto, simultaneamente a defesa dos interesses públicos, por concorrerem indissociavelmente para a satisfação deles. ${ }^{4}$

No entanto, esta dualidade de interesses do Estado, preservando em certos momentos seu próprio interesse e em outros a sociedade deve ser interpretado como um meio em que os interesses da sociedade devem ser sobrepujados em relação aos interesses "particulares" do próprio Estado, ao ponto que na inversão destes papéis, o ato ou contrato administrativo realizado sem o interesse público configura desvio de finalidade. ${ }^{5}$

Enfatizando a assertiva acima, Renato Alessi preleciona que os interesses secundários do Estado só podem ser por ele buscados quando coincidentes com os interesses primários, isto é, com os interesses públicos propriamente ditos. ${ }^{6}$

Por mais natural que sejam estes entendimentos em uma sociedade acostumada com os rigores democráticos, o meio ambiente no Brasil vem colecionando embates em julgados jurídicos, que impõem a proteção do meio ambiente em face da sanha arrecadatória do Estado. ${ }^{7}$

Entretanto, retornando ao tema central do presente artigo, em que o particular figura no diálogo principal com o Estado, temos que a doutrina necessita da exploração dos recursos naturais para a consecução de seu objetivo maior, qual seja a produção de produtos em massa para uma sociedade cada vez mais consumista e dependente destes, gerará na interpretação final um maior ganho ao particular e ao Estado, através dos tributos arrecadados para a manutenção de

\footnotetext{
${ }^{4}$ MELLO, Celso Antônio Bandeira de. Curso de Direito Administrativo. 19 ed. São Paulo: Malheiros, 2005, p.55.
}

${ }^{5}$ MEIRELLES, Hely Lopes. Direito Administrativo Brasileiro. 22ª ed. São Paulo: Malheiros, 1997, p. 81.

${ }^{6}$ ALESSI apud MELLO, Celso Antônio Bandeira de. Curso de Direito Administrativo. 19 ed. São Paulo: Malheiros, 2005, p.56.

${ }^{7}$ STJ. AgRg na SS n. 693/DF, publicado em 20.9.1999, Corte Especial, Ministro Antônio dePádua Ribeiro.

${ }^{8}$ STF. AgRg na STA n. 112-7/PR, publicado em 4.4.2008, e o AgRg. na STA n. 118-6/RJ, publicado em 29.2.2008, Ministra Ellen Gracie. 


\section{REVI STA ELETRÔNI CA DA FACULDADE DE DI REITO DE FRANCA \\ www.revista.direitofranca.br \\ v. 7, n.1, jul/ 2013, I SSN: 1983-4225}

sua estrutura, que não convém dizer neste momento se dispendiosa por demais sem a devida contraprestação ou não, afinal, não é o tema chave do trabalho.

Desta premissa, nasce o ideal do exploracionismo, marcado pela busca incessante de lucros e dividendos.

No entanto, a partir da Declaração de Estocolmo sobre o Meio Ambiente Humano, formatado e fomentado em 1972 pela Conferência das Nações Unidas sobre o Meio Ambiente Humano, inicia-se um movimento que interpretamos de forma a deixar a forma de exploração dos recursos naturais e permitir um modo de utilização destes recursos de forma mais racional e comedida, sem confundir com a visão simplista de tão somente preservá-los, segundo nosso entendimento. ${ }^{9}$

Esta visão pode ser corroborada pelo princípio 21 da Declaração de Estocolmo sobre o Meio Ambiente Humano, em que prega o seguinte:

\footnotetext{
Em conformidade com a Carta das Nações Unidas e com os princípios de direito internacional, os Estados têm o direito soberano de explorar seus próprios recursos em aplicação de sua própria política ambiental e a obrigação de assegurar-se de que as atividades que se levem a cabo, dentro de sua jurisdição, ou sob seu controle, não prejudiquem o meio ambiente de outros Estados ou de zonas situadas fora de toda jurisdição nacional. ${ }^{10}$
}

Desta nova motivação, desperta o pensamento da exploração dos recursos ambientais de forma responsável ao estabelecer uma fase de conservação destes recursos, mas entendido isto como a permissão de exploração dos recursos naturais de maneira racional e sem causar desperdício ${ }^{11}$.

Posta a noção de conservacionismo, pois o princípio 08 da Declaração de Estocolmo sobre o Meio Ambiente Humano indica a necessidade de desenvolvimento para a geração da própria proteção ao meio ambiente, ao expor o seguinte:

\footnotetext{
${ }^{9}$ GRANZIERA, Maria Luiza Machado. Direito Ambiental. $2^{\text {a }}$ ed. São Paulo: Atlas, 2011, p. 23.

${ }^{10}$ Idem, p. 23.

${ }^{11}$ Idem, p. 27.
} 


\section{REVI STA ELETRÔNI CA DA \\ FACULDADE DE DI REITO DE FRANCA \\ www.revista.direitofranca.br \\ v. 7, n.1, jul/ 2013, I SSN: 1983-4225}

O desenvolvimento econômico e social é indispensável para assegurar ao homem um ambiente de vida e trabalho favorável e para criar na terra as condições necessárias de melhoria da qualidade de vida. ${ }^{12}$

E, como devemos olhar para o passado para termos uma singela noção do que poderá ocorrer no futuro, temos que mesmo após vinte anos da realização da Declaração de Estocolmo, eis que em 1992, no Rio de Janeiro, através da Conferência das Nações Unidas sobre Ambiente e Desenvolvimento, a chamada ECO/92, com o objetivo de estabelecer uma nova e equitativa parceria mundial através da criação de novos níveis de cooperação entre os Estados, os sectoreschave das sociedades e os povos, foram formulados novos princípios, que contêm praticamente a mesma diretiva da Declaração de Estocolmo.

Esta visão comprova que mesmo com o passar do tempo, e dizemos de duas décadas, as diretrizes de desenvolvimento continuam as mesmas, sinalizando que as futuras legislações não serão mais compatíveis com o intento preservacionista, tão somente.

Inferimos esta assertiva através do segundo princípio da Conferência ECO/92, ao abordar o mesmo tema do princípio 21 da Declaração de Estocolmo, constando naquele o seguinte:

Os Estados, de acordo com a Carta das Nações Unidas e com os princípios de direito internacional, têm o direito soberano de explorarem os seus próprios recursos de acordo com as suas políticas de ambiente e desenvolvimento próprias, e a responsabilidade de assegurar que as atividades exercidas dentro da sua jurisdição ou controlo não prejudiquem o ambiente de outros Estados ou de áreas para além dos limites da jurisdição nacional. ${ }^{13}$

Maximizando, portanto, o entendimento quanto ao empreendimento de um necessário e essencial procedimento conservacionista de forma a manter o desenvolvimento dos países pela grande necessidade na geração de riqueza, empregos e alimentos.

Nesta concepção, começam a progredir as noções de desenvolvimento sustentável e de novas formas de meio ambiente, que não apenas a natural, na qual passaremos a tratar das

\footnotetext{
${ }^{12}$ Idem.

${ }^{13}$ Idem, p. 28.
} 


\section{REVI STA ELETRÔNI CA DA \\ FACULDADE DE DI REITO DE FRANCA \\ www.revista.direitofranca.br \\ v. 7, n.1, jul/ 2013, I SSN: 1983-4225}

normas-princiológicas para em outro momento tecer comentários sobre as novas espécies de meio ambiente.

\subsection{A MUTABILIDADE FORMAL}

\subsubsection{DESENVOLVIMENTO LEGISLATIVO}

Conforme já abordado, o tema a ser exposto é outro, que não o desenvolvimento histórico do direito ambiental, quando a intenção é buscar justamente sua transformação e não algo que já ficou como aprendizado para os dias atuais.

No entanto, forçoso reconhecer a necessidade de exemplificação de alterações pela mutação formal, que o leitor pode querer se deparar com a indicação de normas passadas, sendo que faremos para o momento a título apenas de indicação, não de comento.

\begin{tabular}{|c|c|}
\hline Ano & Norma Legal \\
\hline 1934 & $\begin{array}{l}\text { Decreto } \mathrm{n}^{0} 23.793 \text {, de } 23 \text { de janeiro - } \\
\text { Aprova o Código Florestal. } \\
\text { Decreto } \mathrm{n}^{\circ} \text { 24.643, de } 10 \text { de julho } \\
\text { Código de Águas. }\end{array}$ \\
\hline 1962 & $\begin{array}{l}\text { Lei Delegada } \mathrm{n}^{0} 10 \text {, de } 11 \text { de outubro - Cria } \\
\text { a Superintendência do Desenvolvimento da } \\
\text { Pesca - SUDEPE . }\end{array}$ \\
\hline 1965 & $\begin{array}{l}\text { Lei } \mathrm{n}^{\circ} 4.771 \text {, de } 15 \text { de Setembro - Institui o } \\
\text { novo Código Florestal. }\end{array}$ \\
\hline 1967 & $\begin{array}{l}\text { Lei } \mathrm{n}^{0} 5.227 \text {, de } 18 \text { de janeiro - Dispõe } \\
\text { sobre a política econômica da borracha e } \\
\text { regula sua execução. } \\
\text { É criada a Superintendência da Borracha - } \\
\text { SUDHEVEA. }\end{array}$ \\
\hline 1967 & $\begin{array}{l}\text { Decreto-Lei } n^{0} 221 \text {, de } 28 \text { de fevereiro - } \\
\text { Dispõe sobre a proteção e estímulos à } \\
\text { pesca. } \\
\text { Decreto-Lei } n^{0} 289 \text {, de } 28 \text { de fevereiro - }\end{array}$ \\
\hline
\end{tabular}




\section{REVI STA ELETRÔNI CA DA \\ FACULDADE DE DI REI TO DE FRANCA \\ www.revista.direitofranca.br \\ v. 7, n.1, jul/ 2013, I SSN: 1983-4225}

\begin{tabular}{|c|c|}
\hline & 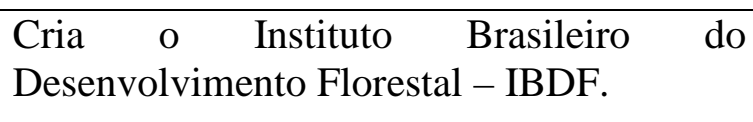 \\
\hline 1972 & Conferência de Estocolmo. \\
\hline 1973 & $\begin{array}{l}\text { Decreto } \mathrm{n}^{0} 73.030 \text {, de } 30 \text { de outubro - Cria, } \\
\text { no âmbito do Ministério do Interior, a } \\
\text { Secretaria Especial do Meio Ambiente - } \\
\text { SEMA. }\end{array}$ \\
\hline 1981 & $\begin{array}{l}\text { Lei } \mathrm{n}^{0} 6.938 \text {, de } 31 \text { de agosto - Dispõe } \\
\text { sobre a Política Nacional do Meio } \\
\text { Ambiente, seus fins e mecanismos de } \\
\text { formulação e aplicação Constituição do } \\
\text { Sistema Nacional do Meio Ambiente - } \\
\text { SISNAMA. } \\
\text { É criado o Conselho Nacional do Meio } \\
\text { Ambiente - CONAMA. }\end{array}$ \\
\hline 1985 & $\begin{array}{l}\text { Decreto } \mathrm{n}^{\circ} 91.145 \text {, de } 15 \text { de março - Cria o } \\
\text { Ministério do Desenvolvimento Urbano e } \\
\text { Meio Ambiente, dispõe sobre sua estrutura, } \\
\text { transferindo-lhe os órgãos que menciona (o } \\
\text { CONAMA e a SEMA). } \\
\text { Lei n } \mathrm{n}^{\circ} 7.347 \text {, de } 24 \text { de julho - Disciplina a } \\
\text { ação civil pública de responsabilidade por } \\
\text { danos causados ao meio ambiente, ao } \\
\text { consumidor, a bens e direitos de valor } \\
\text { artístico, estético, histórico, turístico e } \\
\text { paisagístico. }\end{array}$ \\
\hline 1986 & $\begin{array}{l}\text { Resolução CONAMA n }{ }^{\circ} 01 / 86 \text { - Estabelece } \\
\text { critérios básicos e diretrizes gerais para o } \\
\text { RIMA. }\end{array}$ \\
\hline 1988 & Constituição Federal, art. 225. \\
\hline 1989 & $\begin{array}{l}\text { Lei } \mathrm{n}^{0} 7.732 \text {, de } 14 \text { de fevereiro - Dispõe } \\
\text { sobre a extinção de autarquias e fundações } \\
\text { públicas federais (SUDHEVEA e IBDF). } \\
\text { Lei } \mathrm{n}^{0} 7.735 \text {, de } 22 \text { de fevereiro - Dispõe }\end{array}$ \\
\hline
\end{tabular}




\section{REVI STA ELETRÔNI CA DA \\ FACULDADE DE DI REITO DE FRANCA \\ www.revista.direitofranca.br \\ v. 7, n.1, jul/ 2013, I SSN: 1983-4225}

\begin{tabular}{|c|c|}
\hline & $\begin{array}{l}\text { sobre a extinção de órgão e de entidade } \\
\text { autárquica - SEMA e SUDEPE, cria o } \\
\text { Instituto Brasileiro do Meio Ambiente e } \\
\text { dos Recursos Naturais Renováveis - } \\
\text { IBAMA. } \\
\text { Lei n }{ }^{\circ} 7.797 \text {, de } 10 \text { de julho - Cria o Fundo } \\
\text { Nacional do Meio Ambiente (FNMA). }\end{array}$ \\
\hline 1992 & $\begin{array}{l}\text { Lei }{ }^{\circ} \text { 8.490, de } 19 \text { de novembro - Dispõe } \\
\text { sobre a organização da Presidência da } \\
\text { República e dos Ministérios, transformando } \\
\text { a SEMAM/PR em Ministério do Meio } \\
\text { Ambiente. } \\
\text { Conferência do Rio ou ECO-92 } \\
\text { (Conferência das Nações Unidas sobre } \\
\text { Meio Ambiente e Desenvolvimento), } \\
\text { aprovando a Agenda 21, a Convenção } \\
\text { sobre Mudanças Climáticas, a Convenção } \\
\text { sobre a Diversidade Biológica e a } \\
\text { Declaração do Rio sobre Meio Ambiente e } \\
\text { Desenvolvimento. }\end{array}$ \\
\hline 1993 & $\begin{array}{l}\text { Lei } n^{\circ} 8.746 \text {, de } 09 \text { de dezembro - Cria o } \\
\text { Ministério do Meio Ambiente e da } \\
\text { Amazônia Legal, altera a redação de } \\
\text { dispositivo da Lei } n^{0} \text { 8.490, de } 19 \text { de } \\
\text { novembro de 1992. }\end{array}$ \\
\hline 1995 & $\begin{array}{l}\text { Medida Provisória } n^{\circ} 813 \text {, de } 1^{\circ} \text { de janeiro - } \\
\text { Dispõe sobre a organização da Presidência } \\
\text { da República e dos Ministérios. } \\
\text { Transforma o Ministério do Meio } \\
\text { Ambiente e da Amazônia Legal em } \\
\text { Ministério do Meio Ambiente, dos } \\
\text { Recursos Hídricos e da Amazônia Legal. }\end{array}$ \\
\hline 1997 & $\begin{array}{l}\text { Lei } \mathrm{n}^{\circ} \text { 9.433, de } 8 \text { de janeiro - Institui a } \\
\text { Política Nacional de Recursos Hídricos e } \\
\text { cria o Sistema Nacional de Gerencia-mento } \\
\text { de Recursos Hídricos. }\end{array}$ \\
\hline 1998 & $\begin{array}{l}\text { Lei } n^{0} 9.605 \text {, de } 12 \text { de fevereiro - Dispõe } \\
\text { sobre as sanções penais e administrativas }\end{array}$ \\
\hline
\end{tabular}




\section{REVI STA ELETRÔNI CA DA \\ FACULDADE DE DI REITO DE FRANCA \\ www.revista.direitofranca.br \\ v. 7, n.1, jul/ 2013, I SSN: 1983-4225}

\begin{tabular}{|c|c|}
\hline & $\begin{array}{l}\text { derivadas de condutas e atividades lesivas } \\
\text { ao meio ambiente, e dá outras providências. }\end{array}$ \\
\hline 1999 & $\begin{array}{l}\text { Medida Provisória } \mathrm{n}^{\circ} \text {. } 1.795 \text {, de } 1^{\circ} \text { de } \\
\text { janeiro - Dispõe sobre a organização da } \\
\text { Presidência da República e dos Ministérios, } \\
\text { e dá outras providências. Transforma o } \\
\text { Ministério do Meio Ambiente, dos } \\
\text { Recursos Hídricos e da Amazônia Legal em } \\
\text { Ministério do Meio Ambiente. } \\
\text { Lei n }{ }^{\circ} 9.795 \text {, de } 27 \text { de abril - Dispõe sobre } \\
\text { a educação ambiental e institui a Política } \\
\text { Nacional de Educação Ambiental. } \\
\text { Decreto } \mathrm{n}^{\circ} \text { 3.179, de } 21 \text { de setembro - } \\
\text { Dispõe sobre a especificação das sanções } \\
\text { aplicáveis às condutas e atividades lesivas } \\
\text { ao meio ambiente. }\end{array}$ \\
\hline 2000 & $\begin{array}{l}\text { Lei } n^{0} 9.966 \text {, de } 28 \text { de abril - Dispõe sobre } \\
\text { a prevenção, o controle e a fiscalização da } \\
\text { poluição causada por lançamento de óleo e } \\
\text { outras substâncias nocivas ou perigosas em } \\
\text { águas sob jurisdição nacional. } \\
\text { Lei }{ }^{\circ} 9.984 \text {, de } 17 \text { de julho - Dispõe sobre } \\
\text { a criação da Agência Nacional de Águas } \\
\text { (ANA). } \\
\text { Lei } n^{\circ} \text { 9.985, de } 18 \text { de julho - Institui o } \\
\text { Sistema Nacional de Unidades de } \\
\text { Conservação da Natureza (SNUC). }\end{array}$ \\
\hline 2012 & 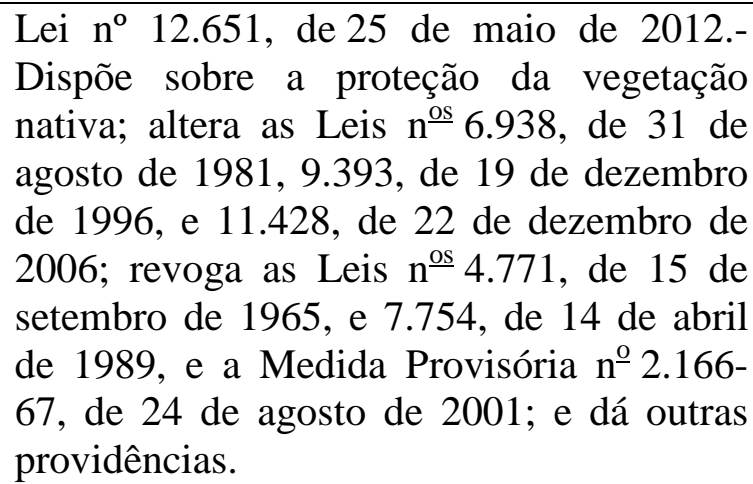 \\
\hline
\end{tabular}




\section{REVI STA ELETRÔNI CA DA \\ FACULDADE DE DI REITO DE FRANCA \\ www.revista.direitofranca.br \\ v. 7, n.1, jul/ 2013, I SSN: 1983-4225}

\section{A PRIVATIZAÇÃO DA DEFESA DO MEIO AMBIENTE: NOVOS INSTITUTOS JURÍDICOS RELACIONADOS AO NOVO CÓDIGO FLORESTAL.}

O tema central do artigo está ligado ao fato de que o mundo passa por transformações quanto ao tipo de Estado necessário para o desenvolvimento deste próprio e da sociedade.

O Estado Social, tal como previsto há tempos já não mais consegue manter os níveis idealizados pelo Welfare State ou Estado de Bem Estar Social, daí a grave crise global nos dias atuais.

A própria manutenção do Estado de Bem Estar Social determinou a alteração do Estado Social para o Estado Pós-Social, em transformação que ocorre há pelo menos 20 anos no resto do mundo e somente a partir de 2004, por intermédio da Lei das Parcerias Público-Privadas, que esta nova figura vem sendo aplicada paulatinamente em nosso País.

A autora portuguesa, Maria João Estorninho, divide sua obra em quatro fases distintas em que o Estado vem figurando de maneiras diferentes quanto à sua ingerência sobre o particular. ${ }^{14}$

Em um primeiro momento, com o surgimento do Estado Absoluto, a distinção entre Estado e Fisco era proposital, uma vez que o Monarca detinha o poder público, mas ausente a personalidade jurídica nesta sua representação. Enquanto, o Fisco não possuía o poder público, mas estava presente a personalidade jurídica do Estado representado neste ente. ${ }^{15}$

Desta forma, o Monarca regulava a vida cotidiana do indivíduo sem que deixasse transparecer a responsabilidade do Estado sobre a norma imposta, consubstanciando tal responsabilidade na pessoa do Fisco, ou seja, o Estado interferia na vida do súdito, de forma truculenta, sem assumir o ônus ou a responsabilidade desta ingerência. Era a expressão da analogia, brilhantemente, citada pela autora portuguesa citada acima como a dupla personalidade, a dualidade de Dr. Jekyll e Mr. Hyde. ${ }^{16}$

14 ESTORNINHO, Maria João. A fuga para o direito privado. Lisboa: Almedina, 1999, p. 14.

15 Idem, p. 25.

16 Idem, p. 23. 


\section{REVI STA ELETRÔNI CA DA \\ FACULDADE DE DI REITO DE FRANCA \\ www.revista.direitofranca.br \\ v. 7, n.1, jul/ 2013, I SSN: 1983-4225}

Findo o Estado Absoluto (L'Etat c'est moi), surge o Estado Liberal em um momento em que passa a vigorar o laissez-faire, onde o Estado opera a transformação do indivíduo de súdito para cidadão, procurando debelar as mazelas do antigo regime.

Por esta razão, o Estado se configura em um Estado de Polícia, pois busca a quebra da intervenção anteriormente imposta sobre o indivíduo, deixando que este regulasse sua vida, buscando tão apenas se adequar a sua liberdade aos limites impostos pelo Estado, ou seja, enquanto o Estado era dado a realizar tudo aquilo que a Lei permitia (surgimento do princípio da legalidade), o cidadão possuía a liberdade de realizar tudo aquilo que a Lei não proibisse.

Nesta época surgem duas idéias fundamentais: a de liberdade e de separação dos poderes. $^{17}$

Entretanto, o Estado foi considerado inoperante nesta fase, pois através da noção de liberdade entregue ao cidadão da época, o Poder Público negligenciou o desenvolvimento da sociedade por estar presente o sentido liberal de governar com o temor de repetir a extrema intervenção do Estado na sociedade.

A forma de impedir nova intervenção do Estado na esfera de liberdade do indivíduo resultou na teorização de limites rígidos para as ações do Estado, operando o surgimento do ato administrativo e sua submissão ao Direito, surgindo consequentemente, o Direito Público, assente na limitação do Poder do Estado, não mais apenas enquanto Fisco, mas através da união de suas personalidades e o aparecimento de uma única figura, dotada de prerrogativas e obrigações. ${ }^{18}$

Com a imobilidade social deixada pelo Estado Liberal, surge o Estado Social, em um novo experimento contrário ao existente no regime anterior.

O Estado Social caracteriza-se pelo fair elle même, pelo Estado Providência, em que novamente o indivíduo não é visto mais como cidadão, mas como utente, tal o inchaço de responsabilidades que o Poder Público toma para si, como podemos exemplificar pela Constituição Federal de 1988, quando Ulisses Guimarães emitiu sua qualificação como “Constituição Cidadã”.

17 Idem, p. 30.

18 Idem, p. 33. 


\section{REVI STA ELETRÔNI CA DA \\ FACULDADE DE DI REITO DE FRANCA \\ www.revista.direitofranca.br \\ v. 7, n.1, jul/ 2013, I SSN: 1983-4225}

Esta nova fase engloba as obrigações principais somadas às obrigações auxiliares, isto é, foi deixado para trás a figura de uma Administração Pública inoperante, abstencionista para voltarmos a uma figura intervencionista, apesar dos limites impostos pela Constituição Federal, no artigo 170, referente aos limites da intervenção do Estado no domínio econômico.

Este novo modelo exige uma atuação da Administração Pública com maior eficácia, autonomia e fiscalização $^{19}$, pois o acúmulo de obrigações e serviços a serem prestados pelo Poder Público aumentara de tal forma que a própria máquina da Administração não suportou tantos deveres, tendo em vista que não deixou no passado as mazelas e máculas geradas pelo Estado Absoluto e Estado Liberal, onde o Estado se caracterizou também apenas pela arrecadação sem distribuição, persistindo tal problema nos dias atuais, mas com inúmeras outras obrigações a serem prestadas.

Isto não quer dizer que o Estado Social seja um problema, uma vez que a decorrência do problema está assente em uma prática ideológica arrecadatória e sugadora não deixada para trás, isto sim, representando o "Custo Brasil”, que é cobrado de seus pseudo-utentes pelas várias obrigações principais (saúde, segurança, educação, moradia, soberania etc) deixadas de lado, apesar do princípio da legalidade e sua cofiguração na Constituição Federal, principalmente nos artigo $5^{\circ}$ a $7^{\circ}$.

Assim, na Europa o Estado Social foi deixado já na década de 90, sendo que o Brasil passa a ter esta experiência apenas por volta de 2004, com a fixação de políticas que buscam a transferência desta responsabilidade social, derivando este novo modelo de Estado como Estado Pós-Social.

No Estado Pós-Social vige o faire-faire, submetendo o Estado Providência ao Estado Garante, uma vez que este possui como característica a defini-lo distintamente dos demais modelos o fato de que a Administração estar voltada para a realização de infra-estrutura, planejamento, gestão, fomento ${ }^{20 .}$ Deixamos de presenciar a prestação estatal, inoperante em nosso País, para defrontar com o garantidor. De realizador para gestor.

19 Idem, p. 39.

20 Idem, p. 102. 


\section{REVI STA ELETRÔNI CA DA \\ FACULDADE DE DI REI TO DE FRANCA \\ www.revista.direitofranca.br \\ v. 7, n.1, jul/ 2013, I SSN: 1983-4225}

É a própria transformação do Direito que passaremos a enfrentar nos tempos vindouros, tendo em vista que as várias formas e modelos de Estado restaram por superados ou falidos, sempre em detrimento de seus administrados.

Esta falência do Estado repercute sempre no indivíduo, pois este é o destinatário final de toda manifestação que parta daquele, resultando que quando foi passada a responsabilidade ao Estado, este pouco fez, mas continuou acionando sua imposição arrecadatória sob o manto da prestação de obras e serviços públicos, minimamente realizados.

A partir do momento em que o Estado se deparou com esta realidade, de assunção de responsabilidades e mínima eficiência pública na entrega destas responsabilidades ao administrado e a necessidade cada vez mais voraz de alimentar a máquina estatal, passou-se à realização das privatizações.

O Estado Social em crise, ou melhor, falido, aumentou as privatizações com o intuito de se eximir da responsabilidade social assumida derivada da promulgação da "Constituição Cidadã”.

Por isso, Estorninho entrega à sua obra o título de "A Fuga para o Direito Privado" ao alertar sobre a necessidade de um estudo sobre a "actividade de direito privado da Administração Pública"21

Portanto, a figura de feitor para gestor encontra guarida também no novo Código Florestal, em que ao comparar a sistemática com a do antigo código, em que tínhamos a ingerência do Estado sobre a propriedade privada de modo a limitá-la a ponto de torná-la por demais onerosa ao proprietário, atualmente contamos com nova codificação que agregará a estas áreas verdes, até então tidas como inutilizáveis, uma revigorosa interpretação de que passarão a resultar recursos financeiros a seus proprietários, pois passa a aliar o desenvolvimento sustentável com a noção de conservação.

O novo Código Florestal não determina a derrubada da mata para a produção agrícola, mas determina que as áreas a serem recuperadas poderão contar com novos institutos hábeis a

\footnotetext{
${ }^{21}$ ESTORNINHO, Maria João. A fuga para o direito privado. Lisboa: Almedina, 1999, p.42.
} 


\section{REVI STA ELETRÔNI CA DA \\ FACULDADE DE DI REITO DE FRANCA \\ www.revista.direitofranca.br \\ v. 7, n.1, jul/ 2013, I SSN: 1983-4225}

resultar em condições financeiras ao seu proprietário para que possa, agora de fato, conservar estas áreas verdes com recursos originários destas próprias áreas.

Na visão antiga, como preservar sem recursos? Como manter uma grande área verde sem uma contraprestação pelos riscos e responsabilidades que originam pela existência desta área?

Lembremos que a responsabilização civil de proprietários que contam com áreas verdes é pela responsabilidade objetiva pelo risco integral, algo impensável até mesmo a ser impingida sobre a Administração Pública, mas que recai com todo seu ônus sobre o proprietário rural.

Essa transformação do Estado acaba também por alterar a visão quanto ao meio ambiente, pois se antes implementava uma política rígida estruturada em um Estado arcaico, atualmente a transferência do cuidar das áreas protegidas cabe ao proprietário, que obedecendo as limitações do novo Código Florestal, poderá usufruir destas áreas para gerar riqueza no intuito de assegurar a existência destas áreas protegidas, pois dela retirará renda através do manejo sustentável, isto é, oportunizada a utilização das áreas para incremento financeiro do proprietário e conservação da própria área.

Desta forma, configuramos a privatização da defesa do meio ambiente, que deixa de ser (in)viabilizada exclusivamente sob a égide do Estado para ser feita através do proprietário rural, que poderá usufruir financeiramente da área, limitado ao disposto em lei.

\subsection{UMA BREVE VISÃO SOBRE OS NOVOS INSTITUTOS JURÍDICOS RELACIONADOS AO NOVO CÓDIGO FLORESTAL A IMPLEMENTAR A PRIVATIZAÇÃO DOS MEIOS DE DEFESA DO MEIO AMBIENTE}

A da interpretação ofertada acima, temos que os novos institutos do novo Código Florestal oportunizam ao proprietário rural a usufruição de área protegida, antes tida como intocável, mas que também determina sua conservação por intermédio da sustentabilidade.

O artigo 66 do novo Código Florestal traz a primeira ideia de um novo instituto a privatizar a proteção do meio ambiente. 


\section{REVI STA ELETRÔNI CA DA \\ FACULDADE DE DI REI TO DE FRANCA \\ www.revista.direitofranca.br \\ v. 7, n.1, jul/ 2013, I SSN: 1983-4225}

Assim, para os casos de reserva legal, o proprietário ou possuidor de imóvel rural que detinha, em 22 de julho de 2008, área de Reserva Legal em extensão inferior ao que delimita a lei, poderá regularizar sua situação recompondo a reserva legal, mediante o plantio intercalado de espécies nativas e exóticas, em sistema agroflorestal, limitado ao seguinte:

a) o plantio de espécies exóticas deverá ser combinado com as espécies nativas de ocorrência regional;

b) a área recomposta com espécies exóticas não poderá exceder a 50\% (cinquenta por cento) da área total a ser recuperada.

Reforçando a ideia central de privatização e sustentabilidade, o parágrafo quarto do mencionado artigo não deixa dúvidas ao estabelecer o seguinte: Os proprietários ou possuidores do imóvel que optarem por recompor a Reserva Legal na forma dos $\$ \S 2^{\underline{o}}$ e $3^{\circ}$ terão direito à sua exploração econômica, nos termos desta Lei.

Vige também no atual código a possibilidade de compensação de áreas, sendo necessário, anteriormente, cadastrar a propriedade no Cadastro Ambiental Rural.

Nesta possibilidade de compensação de áreas, fica facultado ao proprietário rural adquirir Cota de Reserva Ambiental (CRA); arrendar área sob regime de servidão rural ou como reserva legal; ou ainda, cadastrar outra área equivalente e excedente à Reserva Legal, em imóvel de mesma titularidade ou adquirida em imóvel de terceiro, com vegetação nativa estabelecida, em regeneração ou recomposição, desde que localizada no mesmo bioma.

Estas possibilidades de compensações denotam, mais uma vez, a privatização dos meios de defesa, pois, se antes era impensável a possibilidade de compra de cotas para regularização de reserva legal, atualmente contamos com esta possibilidade, certamente ainda a ser regulada através de Decreto Federal.

Mas ainda, temos a possibilidade daquele proprietário rural, que possui área de reserva legal maior que o exigido pela legislação ambiental a arrendá-la para aquele que deseja a compensação e regularização de sua reserva legal, gerando frutos financeiros ao proprietário que sempre investiu em área de preservação e poderá utilizar do arrendamento para mantê-la e usufruí-la economicamente em evidente ineditismo na legislação federal. 


\section{REVISTA ELETRÔNI CA DA \\ FACULDADE DE DI REITO DE FRANCA \\ www.revista.direitofranca.br \\ v. 7, n.1, jul/ 2013, I SSN: 1983-4225}

\section{CONCLUSÃO}

As explanações dos vários momentos focados nas alterações das interpretações sobre os conceitos ambientais, notadamente entre os termos conservação e preservação, comprovam a vivacidade do Direito e suas possibilidades de mutação de duas formas: via jurisprudencial e legislativa.

O simples acomodar do profissional do Direito sobre situações vivenciadas não condiz na segurança necessária a postar-se sobre eventual fato concreto e apontar certeiramente o rumo que este irá se desenrolar.

Isto se deve ao fato de que o Direito está ligado à complexidade da sociedade com seus costumes e novos paradigmas que se originam com o passar do tempo, pois o próprio tempo é agente transformador do ser humano, que não se deixa aquietar com o seu passar.

As passagens de interpretações tratadas neste trabalho sejam mutações formais ou materiais, permitem dizer que a sociedade é operativa, sendo o legislador e os Tribunais vias operativas e de imposição destas novas perspectivas sociais.

Assim, quando tratamos no início da rigidez existente entre os conceitos existentes no passado, sobremaneira impostas ao agricultor, também trazemos à luz as novas determinações de uma nova legislação a seguir os passos traçados pela jurisprudência, que ao tratar do assunto no que nós preferimos chamar de diálogo de duas vias, coube estabelecer uma nova ordem sobre ditas relações.

Dito assim, podemos considerar que a sociedade amadurece ao exigir de nossos poderes constituídos a elaboração de leis ou decisões sobre casos sob uma ótica mais harmoniosa e de bom senso em que cada um deve arcar com obrigações na medida de suas responsabilidades.

Desta forma, se o objetivo da Política Nacional de Meio Ambiente não convergia para o que era determinado pelo antigo Código Florestal, atualmente temos um código que atende aos novos conceitos do microssistema jurídico ambiental.

Ao mesmo tempo, o novo texto legal também permite uma real adequação à Constituição Federal de 1988, uma vez que seu artigo 174 traz a ideia de minimizar o garantismo 


\section{REVI STA ELETRÔNI CA DA FACULDADE DE DI REITO DE FRANCA \\ www.revista.direitofranca.br \\ v. 7, n.1, jul/ 2013, I SSN: 1983-4225}

constitucional, pois prevê que o Estado exercerá a função de fiscalização, incentivo e planejamento, inexistindo no texto a expressão executor, ou seja, a Constituição Federal de 1988 já trazia a noção de que seria implementado um Estado Pós-Social, mesmo que iniciado somente em 2004.

Posto isto, estas alterações do Estado permeiam a mutação do ordenamento jurídico, sentido agora no Direito Ambiental através da Lei $\mathrm{n}^{0}$ 12.651/12 e os inéditos institutos que comprovam a transferência de parte desta responsabilidade, principalmente pelo fato de se alterar a visão de preservação tida até então para outra de conservação do meio ambiente em benefício do particular, que terá a contraprestação da usufruição do bem jurídico ambiental.

\section{REFERÊNCIAS BIBLIOGRÁFICAS}

ESTORNINHO, Maria João. A fuga para o direito privado. Lisboa: Almedina, 1999. GRANZIERA, Maria Luiza Machado. Direito Ambiental. $2^{\mathrm{a}}$ ed. São Paulo: Atlas, 2011.

MEIRELLES, Hely Lopes. Direito Administrativo Brasileiro. 22 $2^{\mathrm{a}}$ ed. São Paulo: Malheiros, 1997.

MELLO, Celso Antônio Bandeira de. Curso de Direito Administrativo. 19 ed. São Paulo: Malheiros, 2005.

SIRVINSKAS, Luis Paulo. Manual de direito ambiental. Ed. 9. São Paulo: Saraiva, 2011.

TAVARES, André Ramos. Curso de direito constitucional. 5 ed. São Paulo: Saraiva, 2007. 